\section{Research on migration and health in Chile: pushing forward}

\section{Investigación en migración y salud en Chile: avanzando}

To the Editor:

Migration is defined as the process of moving from one place to another ${ }^{1}$. It has a rather obvious beginning, but the ending is not necessarily clear ${ }^{2}$. The United Nations defines an international migrant as a person who stays outside their usual country of residence for at least one year ${ }^{3}$. Attempts to define migration have been complex and diverse, involving a wide range of contexts, reasons and types of immigrant, from healthy migrants in search of better opportunities, to political refugees escaping civil wars in their countries of origin.

Migration affects the entire world and represents one of the major opportunities for economic, social and cultural integration, and is also a crucial social determinant of health. As Wickramage and Siriwardhana recently stated ${ }^{4}$, this phenomenon is rapidly reshaping the world. For instance, labour migrants are increasingly flowing among low-income and middle-income nations in Asia, Africa, and the Middle East ${ }^{4}$. The same pattern is found in Latin American countries, where intra-regional migration has deepened socioeconomic inequality over the last decades 5 .

It is relevant to understand that the migration experience does not only imply the experience of crossing political frontiers. There are also symbolic frontiers between one community and another, which are separated by cultural differences. Experiences of crossing each frontier -the geographical and the cultural- may occur at different times and may involve different meanings ${ }^{2}$. These complex and dynamic experiences are intimately connected to health and wellbeing ${ }^{6}$. A review of literature conducted by Cabieses in 2011 highlighted how challenging is to conduct research in this topic internationally ${ }^{6}$. The most frequent challenges are: (i) not having population-based surveys aimed for international migrants in most countries of the world; (ii) poor recording of nationality and other migration-related variables in routine records from the health care system and other national records; (iii) the complexity of reaching undocumented migrants who fear prosecution if identified; (iv) not having robust surveillance systems to monitor the living conditions and health of international migrants, and how they are shaped by political decisions and flows over time.

The health of international migrants has been

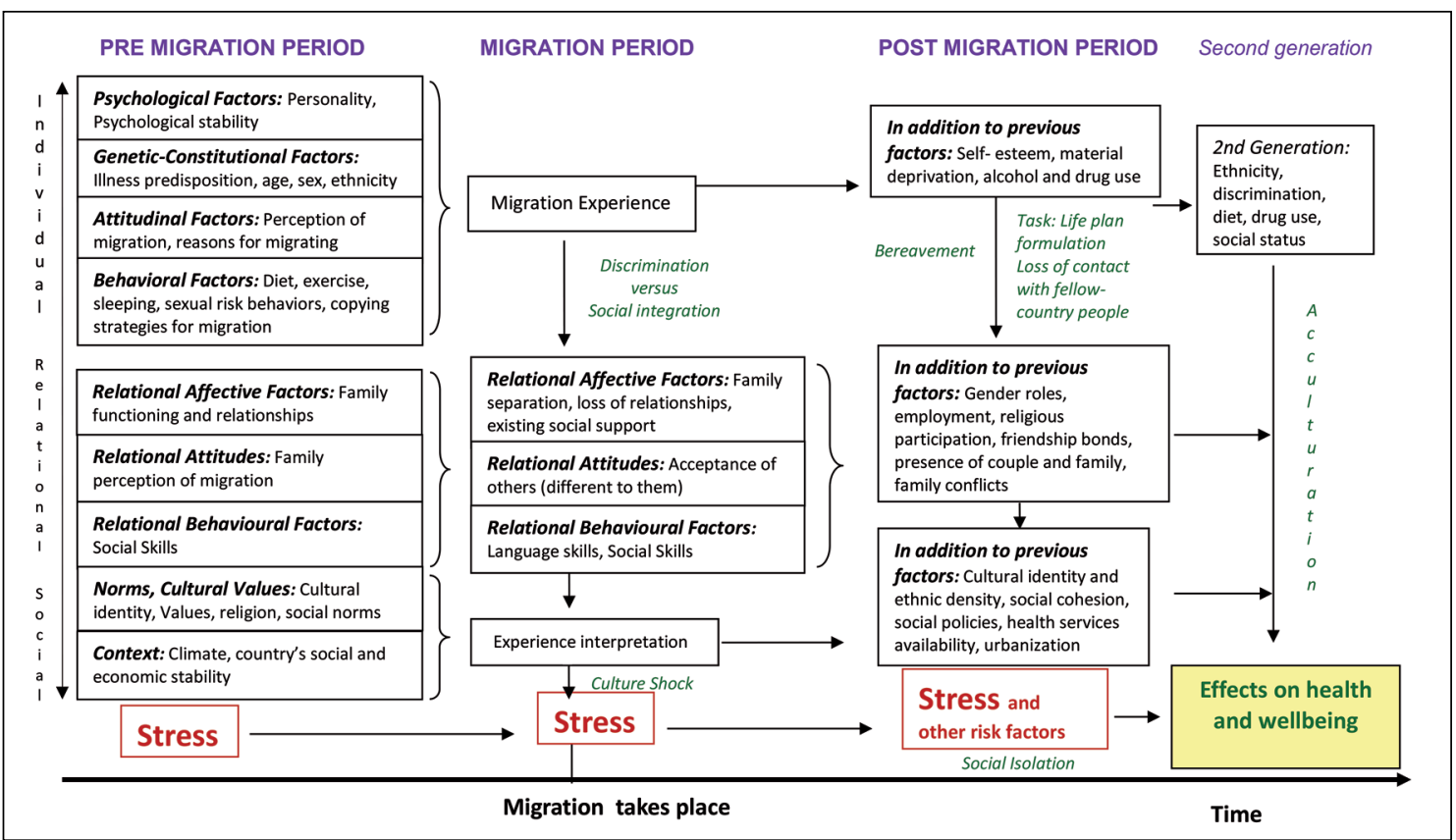

Figure 1. International evidence on factors affecting the health of immigrants before, during and after international migration takes place. *Scoping systematic search conducted in 2009 and updated in 2011 when it has published at http://etheses. whiterose.ac.uk/1935/ (see page 90). Search strategy in PubMed database: "(Migration, Migrants, Immigrants, Emigrants, Mobile population, Spatial mobility, Social mobility) AND (Health, Health outcomes, Health effects, Health consequences, Healthy, Disease, Sickness, IIIness)". 
studied in past years in Chile, largely from a qualitative perspective ${ }^{2}$. Quantitative population-based research suggests the existence of the "migrant effect" for the self-reported immigrant population as a whole (i.e. international migrants report lower prevalence of health problems than the local population $)^{6}$. However, such effect disappears when adjusting for socioeconomic status and length of stay in the country. In some cases, it also fades away for some groups of migrants who come from particular Latin American countries. That is, international migrants living in low socioeconomic status, living in Chile for over 20 years or from Bolivian or Ecuadorian origin might experience similar health issues to the Chilean-born. There is also a group of survey participants in Chile who prefer not to report their migration status and appear as "missing values". Such group, when analysed, is relatively poorer and sicker than self-reported international migrants. This group remains existing in surveys over time in our country (e.g. CASEN survey 2006, 2009, 2011, 2013) and need further attention and discussion ${ }^{6}$.

The purpose of this letter is to advocate for more robust and systematic research on the complex relationship between migration and health in Chile. We need to effectively address well-recognised challenges in this topic and to face the urgent need of improving our surveillance strategies and on-going registries. Moreover, we need to investigate the migration process as a whole and not only when it already has happened. Based on a scoping systematic search conducted in 2009 and updated in $2011^{6}$, Figure 1 displays available international evidence on factors affecting the health of immigrants before, during and after international migration occurred. It suggests that the decisional process of migration, can affect how actual immigration happens and the experience afterwards. Given this evidence, a life trajectory or life course approach to the health of international migrants is recommended, for both research and practice. Some concrete strategies to consider in Chile are: (i) adding questions on the life course and the social determinants to foreigners who enter the country; (ii) improving health care system records with the inclusion of relevant migratory variables as mandatory for both primary and secondary care; (iii) funding specific nationally representative surveys for international migrant populations.
Health of all migrants is an urgent matter, globally. Health is largely protected through protecting every aspect of people's life. Health, as a reflection of social justice, must be explicit in all policies, for local populations and international migrants equally so. Chile has the opportunity to improve the migratory process and the life and health of international migrants, a sub-population that continues to increase over time. Evidence-based, ethically sound, participatory and inter-sectoral strategies have the potential of increasing equity in health for all residents of the Chilean territory today and in the future.

Baltica Cabieses, PhD

Programa de Estudios Sociales en Salud, Facultad de Medicina Universidad del Desarrollo, Chile

Visiting Scholar, Department of Health Sciences University of York, UK Associate epidemiologist, Bradford Institute for Health Research, UK E-mail: bcabieses@udd.cl

\section{References}

1. Tunstall HV, Shaw M, Dorling D. Places and health. Journal of epidemiology and community health 2004; 58 (1): 6-10. Epub 2003/12/20.

2. Stefoni C. Representaciones culturales y estereotipos de la migración peruana en Chile. Santiago de Chile 2001. Available from: http://bibliotecavirtual.clacso.org.ar/ar/libros/ becas/2000/stefoni.pdf.

3. United Nations. World Migration Managing Migration Challenges and Responses for People on the Move 2003. Available from: www.un.org.

4. Siriwardhana C, Wickramage K. Mental health of migrants in low-skilled work and the families they leave behind. The lancet Psychiatry 2016; 3(2): 194-5.

5. IOM. Global migration trends: an overview. Geneva: Migration Research Division, International Organization for Migration. 2014.

6. Cabieses B. The living conditions and health status of international immigrants in Chile: Comparisons among international immigrants, and between them and the Chilean-born York, England: University of York; 2011. 